\title{
La Huasteca colonizada por la explotación petrolera. Tampico, una novela
}

\author{
Edith Negrín \\ Instituto de Investigaciones Filológicas \\ Universidad Nacional Autónoma de México \\ negrin@unam.mx
}

\begin{abstract}
RESUMEN: Este artículo es parte de una amplia investigación que revisa las manifestaciones narrativas sobre el petróleo y la vida social en el México moderno. La saga se inicia en la segunda mitad de la década de los veinte de la anterior centuria, y no es de extrañar que las narraciones iniciales sean de autores extranjeros. Una de las primeras novelas que centra de lleno su argumento en el petróleo mexicano es Tampico, del estadounidense Joseph Hergesheimer, publicada en 1926 y traducida al español en 1929. El presente ensayo se propone presentar a un escritor y una novela apenas conocidos en el campo cultural mexicano. El análisis textual de Tampico muestra su organización interna, tanto como la ideología colonizadora que la sustenta.
\end{abstract}

AвSTRACT: This article is part of a broad research on reviews narrative over oil and social life in modern Mexico. The saga starts in the second half of the twenties of the last century, and no wonders that the initial stories were written by foreign authors. One of the first novels focused in Mexican Petroleum, from the American Joseph Hergesheimer is Tampico, published in 1926 and translated to Spanish in 1929. The present essay intends to present a writer and a novel scarcely known in the Mexican cultural field. Tampico's textual analysis shows its internal organization, and the colonizing ideology that sustains it.

PALABras Clave: novela, historia, petróleo.

KEYwORDS: novel, history, oil.

Luego de las instantáneas de Tampico, ofrecidas por Jack London en 1914 (London 1991), encomiando el orden civilizatorio y tranquilizador que, desde su perspectiva, otorgaban los edificios de las refinerías y las alineaciones de tanques a la feracidad y a la ferocidad selváticas, en 1926 aparece una de las primeras novelas centradas en el petróleo mexicano. Tampico fue publicada en 1926 por el escritor norteamericano Joseph Hergesheimer, quien contribuyó así a fijar los confines de la ciudad portuaria en la geografía de la literatura. 
Tampico, en edición de Alfred A. Knopf (Nueva York), ostenta en la portada la imagen de un hombre gordo de traje y corbata, sentado a una mesa con dos copas, mirando la espalda de una esbelta y atractiva mujer. Ella, vestida con una peineta y un mantón, está de pie y mira hacia el frente. La lectura de la novela permitirá identificar al tipo como el alto empleado de una compañía petrolera norteamericana en Tampico, y a la dama como una de las seductoras jóvenes que laboraban por las noches en los bares de la ciudad. Pedir a los editores coherencia en la vestimenta del hombre, que en la trama se queja siempre del sofocante calor, o conocer la diferencia entre el atuendo de una española y una tampiqueña, tal vez sería exigir demasiado (Hergesheimer 1926).

Un año después de la primera edición, el escritor, en colaboración con Bartlett Cormack, adaptó la novela a una pieza teatral, "Tampico. A Play" (Hergesheimer 2007).

Tampico fue traducida al español en 1929, por Manuel Pumarega, en Madrid bajo el sello de Ediciones Oriente. ${ }^{1}$

\section{UN AUTOR (CASI) OLVIDADO}

Joseph Hergesheimer, prolífico autor de novelas, relatos, ensayos y biografías, nacido en Filadelfia, Pensilvania, en 1880, y fallecido en 1954, es apenas conocido en el panorama de la literatura mexicana actual; de ahí que valga la pena recordar su trayectoria. Muy leído en la década de los veinte de la anterior centuria, llegó a ser considerado por la revista Literary Digest, "el mejor escritor contemporáneo en 1922" (Simpleton). Sin embargo, aún en su país, su popularidad fue disminuyendo en la década siguiente, hasta caer en el olvido.

Educado en la tradición cuáquera, Joseph tuvo una infancia enfermiza que favoreció su inclinación a la lectura. Heredero de una pequeña fortuna, viajó muy joven a estudiar en Italia, guiado por su vocación inicial de pintor, y pasó largas temporadas dedicado a la aventura, la

${ }^{1}$ Joseph Hergesheimer, Tampico, Manuel Pumarega, trad. (1926. Madrid: Editorial Oriente, 1929). Una segunda edición, en la misma editorial y la misma versión en español se publica en 1931, con una modificación en el título: La tierra del petróleo y de la muerte. Tampico. Otras ediciones, con el título de Tampico y la misma traducción son: la de Buenos Aires: Ediciones Siglo XX, 1946, y México: Secretaría de Cultura de Jalisco, 1994. Esta última incluye un prólogo de Mauricio Magdaleno. 
errancia y la disipación. Más adelante, se orientó a la literatura y, al parecer, después de un lapso consagrado a pulir su estilo, dio a la imprenta su primera novela, The Lay Anthony, a los 34 años.

Hergesheimer es definido por la crítica como un "exquisito", un novelista de lujo, devoto del arte por el arte; sus relatos abundan en meticulosas descripciones y avanzan a un ritmo despacioso. Su lenguaje ha sido calificado de florido, extravagante, emperifollado. Se adhiere a una escritura esteticista que encontraba a sus personajes entre los grupos adinerados y fue cultivada en los Estados Unidos antes de la Primera Guerra Mundial, cuando el país descubría a sus clases ociosas, apunta Alfred Kazin. Para este crítico, pese a que Hergesheimer era un narrador nato, no llegó a ser sino "un pintor de corte para los ricos" y un tanto provinciano. La escritura preciosista, uno de cuyos ejemplos mejores es El Gran Gatsby de Scott Fitzgerald (1925), con la Guerra Mundial y la Gran Depresión fue dejando de atraer a los lectores, quienes deseaban reconocerse en obras literarias preocupadas por la problemática social. Es explicable así el gradual desinterés que fue dominando la recepción de los textos del estilista de Filadelfia (Kazin: 231, 242-243).

Sin embargo, no se puede hablar de etapas delimitadas con absoluta precisión; la revista Simpleton, en 1998, en un artículo que aparece sin firma, apunta que en la década de los veinte no se ignoraba si ganaría la batalla de la prosa americana el adornado estilo de Fitzgerald o la musculosa dicción de Hemingway. Lo cierto es que, si bien la escritura de Hemingway se impondría, en el escenario de la posguerra coinciden diversas tendencias, los esteticistas con los escritores más rudos y desilusionados (Simpleton).

Hacia el final de un escrito autobiográfico, From an old house, Hergesheimer menciona un futuro viaje a México, al cual se refiere como un país con el cual había sońado, pero que nunca había visto. Centrando la narración en su residencia campestre, llamada "Dower House", describe con delectación reveladora de sensibilidad plástica, detalles arquitectónicos, estilos de muebles, texturas de alfombras, especies de árboles y flores. Detalla asimismo los cambios que la naturaleza imprime al ámbito inmediato de la casa, a lo largo de las cuatro estaciones. Pero por lo que hace a su vida y trabajo, no es muy explícito. Solo le interesa, en ciertos momentos, especular sobre las mejores condiciones para llevar a cabo su tarea de escritor. Así pues, no esclarece las circunstancias ni las razones del viaje al país vecino. En un pasaje afirma que cuando 
regresara de la ciudad de México el invierno y la nieve se habrían ido, y entonces empezaría un nuevo libro. Poco más adelante explica que si iba a ese país sería porque ya habría terminado su libro en proceso, el de su residencia. Y en la última página afirma que aunque no le gustaba viajar, México lo atraía (Hergesheimer 1925: 211).

No obstante su confeso sedentarismo, ya había publicado, en 1920, una entusiasta crónica de su viaje a Cuba, San Cristobal de la Habana, libro que ha sido reeditado en 2009 y comentado favorablemente por la crítica cubana (Rojas).

De acuerdo con Drewey W. Gunn, Joseph Hergesheimer llega a México en febrero de 1925, creyendo que era invitado del gobierno, hasta que le aclararon su error. Estaba entonces en la cúspide de su fama y buscaba material para una novela. Tras algunas tentativas escribió un guión cinematográfico situado en las minas de plata de Pachuca, en tiempos de Victoriano Huerta, sin embargo, por desacuerdos con el Departamento Mexicano de Asuntos Exteriores, cuando llevó a cabo el rodaje, ese mismo año, la trama se ubicó en California (Gunn: 110). La película, Flower of Night, dirigida por Paul Bern y protagonizada por Pola Negri, está perdida. La anécdota viene al cuento porque algo similar ocurrió posteriormente con su novela petrolera.

El mejor resultado del viaje de Hergesheimer fue que allí le surgió la idea de Tampico, que vio la luz un año después. ${ }^{2}$ El novelista colaboró también en la escritura del guión cinematográfico para filmar la obra, que en 1933 dirigió Irving Cummings. La película, "de acción”, llamada La mujer que robé - The woman I stole —, si bien conserva los nombres de los personajes, sitúa la trama en los campos petroleros árabes (International Movie Database). Parece ser un film bastante mediocre.

Aun cuando en los estudios de literatura mexicana, las alusiones a la novela son escasas, las pocas que existen dejan ver que el autor no está totalmente olvidado.

Julia Hernández, en su recuento de narradores de la Revolución, incluye esta novela, que conoció en la edición de 1932. Le parece que

${ }^{2}$ La información biográfica sobre Hergesheimer en los estudios mexicanos es imprecisa. El cronista Carlos González Salas en su Historia de la Literatura en Tamaulipas — citando el Diccionario biográfico de Historia de México de Juan Gómez de Escalera-, afirma que el escritor norteamericano residió durante un tiempo con su familia en Tampico entre 1919 y 1921. No he encontrado ninguna otra afirmación al respecto (González Salas: 446). 
La tierra del petróleo y de la muerte muestra un "estilo nada original", a excepción de las descripciones de Tampico y de las imágenes petroleras. Para ella el interés de esta narración es conocer la opinión extranjera sobre el país (Hernández: 207-298).

El cronista tampiqueño Carlos González Salas cita en 1984 la opinión de otro cronista, Antonio Martínez Leal, quien en 1977 había escrito un artículo periodístico sobre la novela de Hergesheimer. Comparten ambos el resquemor respecto a la imagen de "desenfreno general" en Tampico que el norteamericano presenta en su novela. Piensan que Hergesheimer no había tenido oportunidad de juntarse con "lo más granado de la sociedad tampiqueña" (González Salas: 445). ${ }^{3}$

Más allá del justificado resentimiento de los tamaulipecos, es el escritor Mauricio Magdaleno en su antología Escritores extranjeros en la Revolución (1979), quien ofrece el juicio más interesante sobre la novela, en su breve presentación del autor norteamericano. A diferencia de Gunn, para quien Tampico "está mejor en el olvido", pues su único mérito reside en ciertas escenas surrealistas, precursoras de la visión pesadillesca sobre México que tendría posteriormente Malcom Lowry, Magdaleno sí aprecia la calidad literaria de la obra, tanto como su valor testimonial. Para él, la novela, una de las más interesantes del autor, recrea "la vida brutal de la Huasteca en días en que el petróleo de la región azuzaba los más implacables apetitos del gran capitalismo norteamericano y europeo, con el consiguiente resultado de una fabulosa erupción de locura de aventureros procedentes de todas partes del país" (Gunn: 110; Magdaleno: 90).

El narrador zacatecano debe haber leído Tampico en la edición original en inglés (1926) pues, un año después, él mismo da a la luz su primera novela, también sobre el tema del petróleo, Mapimi 37.

También se refiere brevemente a Tampico Luis Mario Schneider en su relación de novelas del petróleo. Según el investigador, Hergesheimer es el primero que hizo del tema una creación artística (Schneider: 58).

\footnotetext{
${ }^{3}$ Otras brevísimas menciones se encuentran en el inventario que hace Moisés González Navarro de visitantes extranjeros en México, y en la bibliografía literaria de la Revolución, del blog de Fernando Tola de Habich. Más reciente (2010) es la breve referencia del escritor mexicano Orlando Ortiz, parte de una extensa pesquisa de los escritores forasteros que se han ocupado de la ciudad tamaulipeca (González Navarro: 354; Tola; Ortiz).
} 
James Branch Cabell, escritor amigo y contemporáneo de Hergesheimer, y como él tachado de preciosista, provinciano y superficial por la crítica posterior, publicó en 1921 un "Ensayo de Interpretación" sobre la obra del narrador cuáquero. Branch Cabell se refiere a esos legendarios años que Hergesheimer dedicó a aprender a escribir y apunta que esa labor conforma y colorea cada uno de sus libros. En su opinión, lo más significativo de ese periodo, lo que él llama el "punto de la fábula", es la "ilógica obstinación" del joven Joseph en llevar adelante su propósito de pulir su estilo. Para Branch Cabell, los protagonistas masculinos de su amigo reflejan esa pertinacia, en tanto siempre son seres que consagran cada momento de su vida a perseguir una sola meta (Branch Cabell).

\section{LA NOVELA Y SU PROTAGONISTA}

Tampico es una novela larga, 318 páginas en la edición en español. ${ }^{4} \mathrm{La}$ trama se inicia cuando su protagonista, Govett Bradier, empleado de confianza de una compañía petrolera norteamericana, nombrada como Alianza Petroleum Corporation, o Alianza Oil Corporation, o Alianza Company, regresa al puerto mexicano después de una larga ausencia.

El relato, a cargo de un narrador omnisciente y una secuencia temporal progresiva, está construido con muy pocos acontecimientos y mucha divagación siempre desde la misma perspectiva. El personaje continuamente reflexiona, recuerda, medita, elucubra en una especie de elemental fluir de conciencia que se comunica a través del narrador y no pierde en ningún momento la coherencia racional.

Los acontecimientos, si bien escasos, conforman una intriga casi policiaca, referente a un ataque a la compañía petrolera a la que pertenecía Bradier, a manos de otra empresa competidora, con dosis de suspenso y violencia. Las descripciones de lugares y personas, tan características del estilo de Hergesheimer, ocupan un lugar importante en la trama, pero no interrumpen el ritmo narrativo, más bien contribuyen a la creación de una atmósfera enrarecida. $\mathrm{XX)}$.

${ }^{4}$ La edición empleada en este trabajo es la de 1946 (Buenos Aires: Ediciones Siglo 
En un pasaje, explica el narrador: "la lámpara de petróleo colocada sobre una mesa iluminaba solamente un círculo limitado, más allá del cual la oscuridad iba en aumento hasta esfumar las paredes de la estancia" (136). De alguna manera esta imagen es una metáfora de la novela; las regiones naturales, las calles, las oficinas, casas y bares donde se mueve el protagonista en la Huasteca mexicana constituyen un mundo acotado. Fuera de sus contornos, pese a breves menciones a la ciudad de México, a Nueva York, e incluso a otros países, la realidad parece difuminarse. Solo existe el sofocante Tampico y la visión, el olor y el sonido de sus conductos acuáticos, si bien subyace a los hechos la certeza de que el destino de la región y sus habitantes se define más allá de las fronteras mexicanas.

El extenso relato está dividido en tres grandes secciones, "La factoría marítima", "Zacamixtle" y "La calentura". Comienza con la llegada de Bradier al puerto de Tampico, cuando el barco tanque donde viaja se acerca "a las bajas escolleras que formaba el río Pánuco al desembocar el golfo de México" (7). La salida del alto empleado del territorio mexicano, por la misma vía marítima, va a señalar el final de la narración. El río y el golfo son en la novela presencias constantes. También lo es el petróleo, desde su arribo el hombre contempla el agua del Pánuco "como si fuera una viscosa sábana de aceite" (8).

Los pocos días, no se especifica cuántos, pasados por el funcionario en el puerto y lugares cercanos, constituyen el presente de la historia narrada, una historia que completa su significado al enlazarse, mediante referencias directas, relativamente precisas, a la historia nacional. Aunque, como sabemos, Hergesheimer vino a México en 1925, el personaje Govett Bradier se refiere, como presidente del país durante su estancia, a Álvaro Obregón, cuya administración va de diciembre de 1920 a noviembre de 1924.

Desde este presente, el personaje norteamericano evoca con frecuencia una etapa anterior, en la cual había residido en México durante una larga temporada. De aquella, que él ubica como 20 años atrás, menciona por sus apellidos a los presidentes Porfirio Díaz, León de la Barra, Francisco I. Madero, Victoriano Huerta y Venustiano Carranza. Además de los gobernantes el narrador cita a otros personajes históricos como Manuel Peláez, general de la Huasteca, enemigo de Carranza que, para mantener la región independiente del centro, se alió con las compañías petroleras norteamericanas, organizándoles guardias blan- 
cas. También ofrece Bradier, como ubicación de esa primera estadía suya, la guerra europea.

La narración está asimismo colmada de referencias a lugares reconocibles fuera del texto. Ébano y Zacamixtle; la refinería del Ấguila, la factoría de la Huasteca Company, establecimientos de Tampico como el Hotel Imperial, el Restaurante chino Ciudad de Pekín, el Café Luisiana, el Café de la Ópera, el bar Palais Royal, entre otros. Se mencionan nombres de los pozos, por ejemplo el del Cerro de la Dicha, el Casiano, el de Cerro Azul, y el ferrocarril de la Huasteca.

Sin embargo, no existió ninguna compañía petrolera denominada Alianza Petroleum Corporation, si bien hacia 1924 estaban registradas cerca de 500 compañías petroleras en México (Rippy: 80). La Alianza de la novela está inspirada en alguna de las poderosas empresas norteamericanas, tal vez la Huasteca Petroleum Company, fundada en 1907 por el norteamericano Edward Doheny, que poseía los derechos sobre el pozo Juan Casiano núm. 7 (Villegas Moreno: 33, 38). El rastreo no es fundamental; los perfiles de las compañías petroleras coinciden en buena medida.

La constante comparación de Govett Bradier entre ese antes, y el ahora, va señalando los cambios en el país y en él mismo, siempre con la situación del mineral como eje conductor.

La actualidad aparenta ser armoniosa, como evidencia la placidez de la bien organizada factoría marítima, centro de la sección inicial, donde "en los tanques se derramaba mansamente, sin esfuerzo, el petróleo que llegaba a través de las tuberías desde la manigua remota" (12). Frente a esta impresión, el funcionario rememora una agitada escena en el mismo sitio, observada en su primer viaje. Ahí estaban entonces "ochocientos hombres tendiendo las tuberías desde los pozos hasta el golfo, con los capataces norteamericanos cavadores, pintores y escardadores [...]. Esto había tenido lugar durante la guerra europea, cuando el petróleo alcanzó un precio fabuloso y la concurrencia llegó a todo su apogeo" (53).

El personaje parece haber cambiado también. Diversas voces dan cuenta de que, de joven, había sido fuerte, poderoso y despiadado: "entre los mexicanos había gozado de tanta fama como los cabecillas de bandidos, y se contaban de él toda clase de leyendas. Capaz de beber hasta 72 horas seguidas, todos sus actos y gestos corrían de cantina en cantina. Más de una vez habían intentado matarle...” (50). 
La vida del norteamericano, como la de todos los protagonistas masculinos del autor, estudiados por Branch Cabell, se había movido en torno a un propósito obsesivo: la obtención del hidrocarburo, a costa de lo que fuera. Bradier reseña "la variada y pintoresca película de su vida", que incluye, aún antes de venir a México, "las pardas mesetas de Oklahoma, impregnadas de petróleo; los almendros floridos de California del Sur, el horizonte infinito de Tejas, el descubrimiento de grandes yacimientos petrolíferos y la instalación de la maquinaria" (217).

Un operario de la Alianza, Deleker, evoca con orgullo las hazañas audaces del elevado funcionario: "cuando el Juan Álamo se puso a echar como un diablo cien mil barriles, el señor Bradier se las arregló con un cilindro de gas vacío y un codo de cañería de ocho pulgadas. Antes de que pudiera hacerse el acoplamiento, el petróleo se metió tan adentro en la tierra que formó un nuevo depósito y la Internacional abrió allí un pozo magnífico" (238).

Deleker revive asimismo, con admiración, la crueldad del estadounidense: "el señor Bradier cogió a un mexicano que estaba robando pertrechos y le arrastró atado con una cuerda por un arroyo de petróleo. El hombre no se murió [...]; pero se quedó para siempre doblado en semicírculo. [...] Los médicos dijeron que el petróleo había impedido que se le rompieran los huesos" (238).

Corrían también historias del atractivo del funcionario para las mujeres: "una vez una muchacha india indeciblemente hermosa, que vivía en un pueblecito de la Laguna de Tamiahua, había visto al señor Bradier pasar en una lancha y se enamoró perdidamente de él" (239).

El propio Govett Bradier se juzga a sí mismo en forma apenas un poco más moderada: "en otro tiempo podía contratar a un simple peón $y$ ponerle al frente de un taller de maquinaria. En caso necesario también había sacrificado la vida de algunos hombres" (13). Resume la etapa de su juventud, durante la presidencia de Carranza, como "tiempos de desenfreno" (18), para él mismo y para el estado:

el Palais Royal había vivido en un estrépito constante y desde sus tres galerías caían sin cesar al patio botellas vacías de cerveza. A cada momento se libraban combates, se oían tiroteos en los arrabales de la ciudad, corrían constantemente rumores de ocupación, las balas silbaban por las calles, los marinos norteamericanos salían vengadoramente de su zona, y 
durante la guerra Europea, esta tensión habíase acrecentado y los recelos imperantes eran agudos y fatales como cuchillos (18).

En el presente de la historia, Govett Bradier cuenta con 44 años de edad, es un hombre debilitado tanto por la enfermedad, el paludismo contraído en su primera estancia en "la tierra caliente", como por la inactividad impuesta para recuperarse. Cuando llega a México por segunda vez tiene el rostro enjuto y cetrino, con un matiz amarillento. La curación a base de quinina le había dejado una secuela de cansancio, trastornos visuales, leve sordera. Padece asimismo a ratos desorden mental, que atribuye a su estancia en los Estados Unidos: "era natural que sus pensamientos se hubieran tornado confusos en las oficinas de la Alianza en Nueva York, donde se sabía muy poco acerca del petróleo y absolutamente nada sobre México" (8). Su laxitud y confusión se intensifican con el alcohol o con la fiebre que nunca lo había abandonado por completo.

Su visión del mundo, aparentemente, también se había modificado en esa segunda residencia en la comarca. Al inicio de la novela, reitera haberse desinteresado de todo, el mineral incluido, y actuar solo en función de un empeño amoroso, estabilizar su relación con la atractiva Vida. Ella era una ambiciosa joven, esposa de un funcionario de la Alianza con la cual, en su permanencia anterior, había iniciado un romance. Sin embargo, pese a sus afirmaciones en contrario, el representante de la empresa de petróleo pronto comprende que la principal seducción de su existencia, continúa siendo el codiciado mineral:

Solamente los escapes de petróleo no habían perdido la fascinación que ejercían sobre él y se paró a contemplar un negro charco de petróleo en cuyo centro estaba formándose una enorme burbuja iridiscente, que acabó por inflamarse y estallar, dejando un instante en la superficie líquida la huella de su circunferencia. Luego se formó otra burbuja que estalló igualmente. Era aquel el extraño mensaje del centro de la tierra, que salía a la superficie como un aviso, como una amenaza. Gases y líquidos abrasadores bajo tremenda presión, mundos de vegetación perdidos y huesos convertidos en piedra, lechos de antiguos mares cubiertos de delicadas conchas: todo lo que en épocas remotas había sido animado por la luz y el aire volvía a la superficie convertido en sólida negrura (76). 
Si a su llegada el confiable representante de la empresa había pensado que la zona estaba en calma, pronto se da cuenta de la falsedad de su apreciación: "el peligro seguía palpándose en el aire como el polvo" (17); "en cualquier momento los rifles mexicanos podían romper el fuego contra la factoría y las balas quebrar los cristales de las ventanas" (60).

Cuando se hacen tangibles las amenazas contra la estabilidad de la empresa, a causa de la traición de otro trabajador, nuestro hombre en Tampico se da cuenta de que él tampoco había cambiado. Guiado por sus mejores sentimientos, y siempre en función de resguardar las operaciones de la Alianza, en un principio se había propuesto proteger a su adversario en amores, el esposo de Vida, Presby Corew. Luego, cuando este es asesinado, el antiguo funcionario cae en la cuenta de que ha perdido toda la pasión por la joven: "por un momento, había fulgurado en él una avalancha de sentimientos, como cuando brota el mineral de un pozo petrolífero; pero luego había venido la esterilidad del agua salobre" (216).

A pesar de su desencanto sentimental, decide ofrecerle a la mujer lo mejor de su persona. Pero sus planes resultan fallidos: es de nuevo atacado por la fiebre palúdica; su supuesta perversidad ha sido asentada en un testimonio escrito por el cónyuge de Vida; y ella, a su vez, viéndolo enfermo y débil, le habla con cruel menosprecio y lo abandona. Lo más doloroso para el antes influyente personaje, es el desamparo de su amada compañía petrolera que, en la crisis, le proporciona apenas el apoyo mínimo para escapar de Tampico.

La muerte de Presby Corew podría desencadenar una intervención norteamericana en Tampico, opinan algunos, como Deleker. Bradier sabe que no será así; que el gobierno mexicano abrirá un expediente, ejecutará a cualquiera, y los Estados Unidos se darán por satisfechos. Los representantes de las compañías petroleras en México no dirán nada, salvo entre ellos: "eso no llegará a Nueva York". "En Washington nadie querría escucharlo" $(261,271)$. La percepción de la insignificancia de los individuos, aun de sus más confiables trabajadores, para las grandes empresas, agudiza la desilusión del funcionario.

La novela finaliza con su salida de Tampico. Govett Bradier "sentíase perdido entre las constelaciones estelares [...]. La campana del barco sonó nuevamente, con una sola nota que fue extinguiéndose, ascendió otra vez y agonizó de nuevo a lo largo de la cubierta. Así terminaría el último acto: en una inmensidad de silencio" (318). 


\section{MiradAS DE LA METRÓPOLI}

Si bien los funcionarios petroleros en la novela muestran diferencias y enemistades profundas entre ellos, sus impresiones de Tampico, al que con frecuencia identifican con México todo, coinciden y, sin duda, corresponden a la visión del autor. Por supuesto, el que con más frecuencia expresa esta perspectiva maniqueísta y conformada con los prejuicios propios del pensamiento capitalista es Govett Bradier.

Si Jack London, en su reportaje sobre la Huasteca, puede contemplar, junto a las instalaciones industrializadoras, la riqueza agrícola de la región, esta no existe para Hergesheimer. El Tampico plasmado en sus páginas es un lugar desagradable desde la mera apariencia: "no ofrecía nada de romántico [...]; era una ciudad fea, al borde de un río teñido de petróleo" (19). Después de su ausencia, Govett la mira como "una ciudad gris, incolora", a pesar de que "se había americanizado mucho [...]; casi no se veían indios ni sarapes, por las calles" $(16,19)$.

Con frecuencia Bradier menciona el sempiterno calor de la región: "la quinina era imprescindible para todo el mundo en la costa mexicana, en la tierra caliente" (8, en cursiva en el texto). Se asocia así la tierra caliente con la enfermedad palúdica transmitida por "un pequeño mosquito", que se manifiesta con la hipertermia, "fiebre subterciana tropical", o "malaria tropical" $(98,102,268)$. Y se equipara esta destemplanza física con otra, la que había regido la vida del norteamericano, la "fiebre del petróleo" (17). En la tercera sección de la novela, titulada "La calentura", el protagonista vuelve a ser intensamente poseído por ambos síntomas febriles, de los que creía haberse recuperado.

Otro asalariado estadounidense, Lentz, culpa al entorno de las extravagancias del funcionario de la Alianza: "usted está loco [...]; eso es el paludismo, señor Bradier, combinado con la influencia de México". "Es una tierra poblada de amenazas misteriosas" $(262,261)$. "La atmósfera de Tampico estaba cargada de influjos corruptores", piensa Govett Bradier. La enfermedad simboliza la corrupción afectiva y moral de la región:

Desde los tiempos de Ébano, Tampico había sido una ciudad singularmente peligrosa y traicionera, un centro de rencores, de codicia y desesperación, de poderes secretos e implacables. Nada era lo que a primera vista parecía. Nada de lo que allí se dijera podía tomarse en consideración. Las palabras solo servían para encubrir móviles criminales (17). 
Sin embargo, el norteamericano es lo suficientemente lúcido para comprender, o al menos intuir, que la problemática de la región obedece al lugar que ocupa en la economía mundial: "Tampico era un campo de batalla privado, en el que se desarrollaban ataques planeados en Londres, Holanda y Nueva York, para cuya ejecución subrepticia se utilizaba la ley, el soborno y la violencia" (17). Los empleados del campamento petrolero

pertenecían a la frontera, en el más amplio y romántico sentido de la palabra, pero a una frontera que el telégrafo mantenía en comunicación constante con Nueva York, Amsterdam y Londres. Era una frontera científica, en la que se mezclaban las pistolas con los cálculos intrincados y la complicada maquinaria, la bravura primitiva con las enseńanzas de las escuelas técnicas (135).

Por su parte, el esposo de Vida, Corew Presby, se refiere al estado como un "extraño infierno", y Deleker - en otro pasaje - concuerda: "este infierno de Tampico, lleno de luces y música" (89, 234). Presby concibe el petróleo como el emblema de la acción destructiva del lugar sobre los hombres: "es como si se vadeara un maldito arroyo de mineral. Sea uno quien sea, al fin y a la postre acabará por mancharse de negro de chapopote" (175).

Solamente un estadounidense, enamorado de una bailarina de un antro, habla bien del país; y eso en un momento de total ebriedad. Sus palabras son transcritas, a través del punto de vista de Bradier, quien les imprime un matiz irónico: "[Hattrick] nuevamente se había puesto a hablar de México, país donde crecía en mayor abundancia la vainilla y donde los periquitos de color esmeralda se posaban por parejas en las ramas de los árboles. Dijo que Pepita era el pájaro de su amor" (246).

La descomposición moral de Tampico se hace evidente en los centros nocturnos, con su "atmósfera de alcohol, cuchicheos, mujeres, violencia”, a los que Bradier era aficionado (148). Las características negativas se encarnan especialmente en las mujeres públicas que laboraban en el "Luisiana", el "Bristol" o el "Bolívar". Esas "muchachas mexicanas" que "usaban polvos fuertemente perfumados", eran completamente distintas de las norteamericanas (149).

El norteamericano afirma conocer bien "a estas desnudas mujeres, productos del cruce de España y México", cuya "turbia y entremezclada 
sangre les imprimía cierta tosquedad una vez pasados los primeros bríos de la juventud". Pese a ello, conservaban en todos sus actos y ademanes "una delicadeza innata" (27).

Tal refinamiento no excluye, según el narrador, que acostumbren llevar una navaja en la liga de la media y la manejen "con suma destreza”. Por citar algunas anécdotas, una bailarina del Bolívar, llamada Ana, le clava el cuchillo en el hombro a un obrero del petróleo una noche, porque este le había impedido apuñalar a otro con quien ella bailaba. Y otra joven, Teresita, de quien se afirma que era cruel porque "tenía sangre india", y había matado a 11 hombres, intenta atacar al propio Bradier con una navaja, si bien finalmente se abstiene de hacerlo porque existía entre ellos cierto afecto $(19,26,39,281,239)$.

La peor de todas las mujeres es Adelina, mujer de Rayón, jefe de los bandidos, caracterizada como un ser de intensa fealdad: "su rostro, cubierto de huesudas prominencias y más blanco que la cara enharinada de un payaso, daba la impresión de una inanimada calavera". Ella es capaz de balacear a un hombre casi por capricho $(188,194)$.

Para Bradier las mujeres eran "fuentes de incalculable peligro, de insondables traiciones", "como un trago de tequila, como una bebida de imprevisibles y malignas potencialidades". Ello se debía a que "este era un mundo totalmente masculino, en el que las mujeres solo aparecían como cosas incidentales [...]. México, los mexicanos y el petróleo eran así por eso" $(147,240)$.

Los nacionales que laboran en la empresa, solo aparecen en calidad de objetos a quienes Bradier, como se ha visto, amenaza o agrede ferozmente, siempre con justa razón, a su entender; el narrador los describe aún más cosificados y carentes de voz que las mujeres de los burdeles.

Los mexicanos que sí actúan en la trama son principalmente los hombres del general Melchor Rayón, clasificado por los estadounidenses como maleante, pese a que hacía gala de un discurso nacionalista. El general arenga a los administradores de un campamento de la Alianza: "[i] es que quieren ustedes apoderarse de nuestro petróleo y nuestra tierra con solo dar dinero y promesas al gobierno de Obregón? ¿Creen ustedes que ya no quedan verdaderos patriotas en México?”. Pero sus intimidaciones resultan ser, en última instancia, un mero recurso para negociar más beneficios. En otro momento, afirma "-Todas las compañías petrolíferas [...] están infringiendo la Constitución de 1917, y yo no estoy de acuerdo con la actitud de Obregón...”. Ante su bravata, 
Bradier reacciona ofreciéndole más dinero: "yo puedo asegurarle a usted que la Compañía tendría mucho gusto en contribuir con cien mil pesos a las necesidades patrióticas" $(139,193)$.

Para el funcionario Govett Bradier, "todos los cabecillas de bandidos se llamaban generales y afirmaban que eran patriotas que defendían a México contra los intereses extranjeros"; todos "eran unos redomados granujas" $(72,95)$.

De Rayón dice Willig, asalariado norteamericano: "es el Peláez de hoy; pero en menor escala [...]. Ahora ha reunido ya de trescientos a quinientos hombres y acabará por hacer la última revolución. Ni qué decir tiene que nosotros lo tenemos a sueldo" (77-78).

Un obrero más, Pine, afirma que en el país "una fiesta patriótica general [...], consistiría en apoderarse de las cosas norteamericanas" (12).

Los hombres de Rayón son descritos por Bradier con desprecio: "eran indígenas corrientes, organizados en todo momento oportuno para el pillaje y el asesinato. Los mexicanos eran hombres de corta estatura y movimientos indolentes que se cubrían con absurdos sombreros de paja de alas enormes. Iban descalzos y llevaban la pistola ciñéndoles su exiguo talle" (126-127). A su vez, el conductor del auto del norteamericano cuenta: "el otro día vi a un mexicano que llevaba en el sombrero una ristra de dedos humanos" (127).

La novela da cuenta de los numerosos chinos que habitan Tampico, dedicados a limpiar las casas, cocinar, cantar o bailar. Un personaje incidental, un inglés cuyo nombre no se menciona, siente por los orientales un desdén análogo al de Bradier por los nativos de México, y compara a un cantante chino con un mico (138).

El protagonista de la novela, tan distante de los mexicanos, se siente no obstante también ajeno a los administrativos de la compañía en Nueva York, en sus ordenadas oficinas "de cristal y caoba", que "parecían dotados de una extraordinaria lealtad. Tanto en su conversación como en sus actos se observaba un aparente candor. Alimentaban grandes utopías sobre el porvenir de los Estados Unidos y sobre la integridad de su comercio; pero, en particular, manifestaban una seguridad absoluta acerca de la naturaleza inagotable de los yacimientos petrolíferos de la costa mexicana" (40).

Tampoco encaja entre los demás representantes de las empresas en Tampico, aquellos que viven en las exclusivas colonias inglesa y norteamericana, y se reúnen en similares "cocktails", fiestas, tés y campos 
de golf $(22,23)$. No embona porque más que con la vida social, está familiarizado con los brutales procedimientos de la compañía en México. No en balde cuenta entre sus hazañas el haber contenido una vez la afluencia de un pozo petrolero con cadáveres, durante el carrancismo (127). Y ya en el presente, amenaza a un obrero con arrojarlo a un depósito de petróleo hirviendo para que confiese acerca de un sospechoso accidente. Luego, reflexiona, siempre a través del narrador: "el indio era un ente sin importancia ante las necesidades de Govett Bradier [...]; ¿qué pesaba en la balanza un mexicano muerto o incluso mutilado?" (119).

En un primer movimiento, el norteamericano suscribe la usual justificación de los capitalistas por sus intervenciones en los países en desarrollo: "solo de admirable podía calificarse a una empresa que llevaba su capital a un país extraño y amigo, abría pozos petrolíferos, transportaba el mineral por medio de tuberías a sus depósitos y barcos, lo refinaba y clasificaba luego y después se lo vendía al público a un justo precio". Pero, a continuación, su sagacidad lo obliga a reconocer en la compañía petrolera "una hipocresía inevitable: el resultado de una civilización opresora" (41). Otro operario llamado Lenz dice a Bradier: "nadie sabe mejor que usted que la obtención del petróleo en este país ha producido una ética peculiar" (308).

No todos los empleados norteamericanos tienen la misma perspicacia. Deleker, por ejemplo, cuando habla de una posible intervención norteamericana en Tampico, afirma con cinismo: "entonces veremos revocado el artículo 27 de la Constitución, y nuestras compañías petrolíferas podrán hacer lo que les dé la gana. Ya nos arreglaremos nosotros para acabar de una vez con los bandidos y con los mosquitos. Y no estaría de más poner coto al movimiento obrero. Si no lo hacemos, México acabará tan mal como Rusia” (271).

De nuevo la asociación entre los mosquitos, transmisores de la enfermedad del trópico y los malhechores que, sin embargo, son los aliados de la compañía.

\section{LAS PARADOJAS DE UN ESCRITOR NORTEAMERICANO}

Séptima novela de Hergesheimer, Tampico está considerada entre las menos artísticas que escribió. Tal vez el choque con la descarnada reali- 
dad del enclave petrolero colonial puso en cuestión, hasta cierto punto, su vocación esteticista.

El relato abunda en informaciones acerca de la apariencia de lugares y personajes, como hemos visto. No obstante, comparado con otros de sus libros, aquí el autor disminuye su delirio descriptivo característico, que algunos lectores encuentran ridículo, de acuerdo con Alfred Kazin (233). Coincide en esta apreciación el citado artículo de la revista Simpleton: "Inverosímil rosa experimental. Joseph Hergesheimer y el futuro de la escritura florida".

Precisamente la escritura de Tampico, de transición entre una inclinación manierista muy apreciada en su momento, si bien rechazada después, y la involuntaria denuncia social, permite que la novela aún pueda ser leída con interés. Su valor, como apunta Magdaleno, es la recreación del momento histórico, la década de los veinte mexicanos en parte de los estados de Tamaulipas y Veracruz; la recuperación de esa atmósfera cargada de incertidumbre y violencia.

En mi opinión es también invaluable el testimonio del punto de vista de los extranjeros que invertían en el petróleo del país a inicios del siglo xx. De manera consciente, Govett Bradier, portavoz privilegiado de Joseph Hergesheimer, manifiesta su perplejidad y horror ante la barbarie mexicana, en tanto excusa - y ejerce - la depredación capitalista. Su arrogancia se sustenta en su convencimiento de la inferioridad de los mexicanos. Aquí viene al caso recordar una reseńa -a la primera edición en inglés-, la única que he encontrado sobre la novela, que el escritor guatemalteco Enrique Gómez Carrillo publicó el diario $A B C$ de Madrid. Bajo el título de "Las mexicanadas de los novelistas yanquis", el autor se burla del trazo positivo del protagonista norteamericano de Tampico: "Govett es, no ya un yanqui, sino un superyanquil" y la correspondiente pintura de los mexicanos como seres inferiores. Esta es, para el crítico, la "nueva visión de Méjico que los norteamericanos se han propuesto imponer al mundo. La novela le recuerda esos films en los que siempre se ve al yanqui, impecable, hermoso y fuerte como un semidios, luchar contra la insidia rampante de los mejicanos" (Gómez Carrillo).

Sin embargo, en mi opinión, existe una cierta ambivalencia en el autor. Pese a su toma de posición, explicitada a través de varios personajes, muestra con nitidez la amoralidad, la ilimitada codicia y el salvajismo de las empresas petroleras y sus representantes. En este sentido, sin duda 
Hergesheimer coincide con un escritor contemporáneo suyo, mucho más complejo, perfecto y canónico, Joseph Conrad. Aunque la visión del mundo no occidental del talentoso novelista Conrad, representan te del imperio británico, está siempre limitada por su perspectiva occidental, como prueba el acucioso análisis de Edward Said, sus narraciones ilustran la barbarie característica de los países colonizadores (20).

A esta ambivalencia del narrador, se debe que Tampico sea calificada como "una de las obras ejemplares del género" de la novela antiimperialista, en el esclarecedor estudio de Luis Alberto Sánchez, y esté situada entre muchas otras narraciones escritas por latinoamericanos. El crítico peruano vincula la exacerbación de la temática antiimperialista —la denuncia de las atrocidades de las compañías fruteras, mineras, petroleras, entre otras - a partir de 1927, en la narrativa latinoamericana, con la rebelión de Augusto César Sandino, ocurrida ese mismo año, y con la "dollar diplomacy" instrumentada por el presidente republicano William Howard Taft (Sánchez: 483). ${ }^{5}$

Si bien es cierto que el presidente demócrata Woodrow Wilson (1913-1921) se comprometió a finalizar con la también llamada "política del dólar”, en la práctica no se apreció el cambio (Meyer: 61). La diplomacia del dólar, ese intervencionismo económico de los Estados Unidos en los países latinoamericanos, se complementaba, por supuesto, con la fuerza militar en cuanto fuera necesario. Francisco Morales Padrón, estudioso de la narrativa hispanoamericana, a propósito del contexto en que fueron escritas muchas novelas antiimperialistas, cita las declaraciones del famoso y condecorado Smedley D. Butler, general brigadier de la infantería de marina, veterano de la toma de Veracruz (Morales Padrón: 147). Butler, en 1935 declaraba:

He pasado treinta y tres ańos y cuatro meses en servicio militar activo de la fuerza militar más diestra del país, el Cuerpo de Marina. Serví en

\footnotetext{
5 Por lo que hace a la "diplomacia del dólar", recibe este nombre la política exterior seguida de 1909 a 1913 por el Presidente William Howard Taft y su Secretario de Estado Philander C. Knox. De acuerdo a ella, el objetivo de la diplomacia era generar en el extranjero el orden y la estabilidad necesarios para promover los intereses comerciales americanos. También implicó usar el capital privado para mejorar los intereses norteamericanos en el extranjero (Office of the Historian, Bureau of Public Affairs. United States Department of State. "Dollar Diplomacy, 1909-1913” U.S. Department of State).
} 
todos los rangos comisionados desde Segundo Teniente hasta MayorGeneral. Durante ese periodo, la mayor parte de mi tiempo actué como un bandido, altamente calificado al servicio de los Grandes Negocios, de Wall Street y de los banqueros. En breve, he sido un pandillero, un gangster al servicio del capitalismo [...] En 1914 ayudé a México, a Tampico en particular, a ser un lugar seguro para los intereses petroleros estadounidenses ${ }^{6}$ [trad. EN].

Las palabras del destacado militar, acerca de los intereses económicos de las empresas, como orientación de la política expansionista norteamericana, a mediados de la década de los treinta, concuerdan perfectamente con el discurso, la visión del mundo y el trazo de un personaje como Govett Bradier, protagonista de una trama publicada nueve años antes.

El valor testimonial de Tampico sin duda desborda las intenciones de su exquisito autor, quien se sentía más a gusto describiendo las finas maderas de los muebles de su casa, que padeciendo el asedio de la incomodidad, el calor y los mosquitos de los pueblos del Golfo de México. Joseph Hergesheimer hubiera rechazado aproximarse a esos intelectuales norteamericanos que, en la década de los veinte, se identificaron con las causas latinoamericanas y se volvieron radicalmente críticos de su situación en el sistema capitalista. Y sin embargo, coincide con ellos en su recreación del mundo colonizado.

\section{BIBLIOGRAFÍA}

Branch Cabell, James. “Joseph Hergesheimer: An Essay In Interpretation”. Chicago: The Bookfellow, 1921, 9. Artículo en línea disponible en <http://www.archive.org/details/josephhergeshei00cabegoog > [fecha de consulta: 3 diciembre, 2012].

${ }^{6}$ No transcribo exactamente la parte citada por Morales Padrón (147), pues me interesa enfatizar el contexto del discurso en que Smedley se refiere a Tampico. Estas palabras del marine norteamericano han sido citadas en innumerables ocasiones: "I spent thirty-three years and four months in active military service as a member of this country's most agile military force, the Marine Corps. I served in all commissioned ranks from Second Lieutenant to Major-General. And during that period, I spent most of my time being a high class muscle-man for Big Business, for Wall Street and for the Bankers. In short, I was a racketeer, a gangster for capitalism. [...] I helped make Mexico, especially Tampico, safe for American oil interests in 1914” (Butler). 
Butler, Smedley. “On War, by U.S. General Smedley Butler, 1933”. Artículo en línea disponible en <co.quaker.org/Writings/SmedleyButler.htm> [fecha de consulta: 3 diciembre 2012].

Gómez Carrillo, E. "Las mexicanadas de los novelistas yanquis". $A B C$ (Madrid), 16 de septiembre, 1927. 3. Artículo en línea disponible en <http://hemeroteca.abc.es/nav/Navigate.exe/hemeroteca/madrid/ abc/1927/09/16/003.html> [fecha de consulta 3 diciembre, 2012].

GonzÁlez Navarro, Moisés. Los extranjeros en México y los mexicanos en el extranjero. 1821-1970, vol. 3. México: El Colegio de México, 1994.

González Salas, Carlos. Historia de la Literatura en Tamaulipas. $2^{\mathrm{a}}$, parte. Tomo

II. Ensayo y narrativa. Tamaulipas, Cd. Victoria, 1984.

Gunn, Drewey Wayne . Escritores norteamericanos y británicos en México, 15561973 (1969). Traducción de Ernestina de Champourcin. México, Madrid, Buenos Aires: Fondo de Cultura Económica, 1977.

Hergesheimer, Joseph. From an old house. Nueva York: Alfred A. Knopf, 1925. Hergesheimer, Joseph. Tampico. Nueva York: Alfred A. Knopf, 1926.

Hergesheimer, Joseph. Tampico [1926]. Traducción de Manuel Pumarega, Madrid: Editorial Oriente, 1929.

Hergesheimer, Joseph. La tierra del petróleo y de la muerte. Tampico (1926). Traducción de Manuel Pumarega, Madrid: Editorial Oriente, 1931.

Hergesheimer, Joseph. Tampico [1926]. Traducción de Manuel Pumarega, Buenos Aires: Ediciones Siglo XX, 1946.

Hergesheimer, Joseph. Tampico [1926]. Traducción de Manuel Pumarega. Prólogo de Mauricio Magdaleno. México: Secretaría de Cultura de Jalisco, 1994.

Hergesheimer, Joseph and Bartlett Cormack. Tampico, a play. Disponible en Guide to the Charles Morton Agency Collection of American Popular Drama. 1842-1950. C 2007. University of Chicago Library. <http://ead.lib.uchicago.edu/learn_on3.php? eadid=ICU.SPCL. MORTONAGENCY\&format $=$ raw $-\mathrm{xml} \&$ collection=project $/$ SCRC\&q=inventory + King XML $>$ [fecha de consulta 3 diciembre, 2012]. Hernández, Julia. Novelistas y cuentistas de la Revolución. México: Unidad Mexicana de Escritores, 1960.

International Movie Data Base. Disponible en <http://www.imdb.es/> [fecha de consulta 3 diciembre, 2012].

KazIN, Alfred. En tierra nativa. Interpretación de medio siglo de literatura norteamericana. Traducción de Juan José Utrilla (1982). México: Fondo de Cultura Económica, 1993.

London, Jack. México intervenido. Reportajes desde Veracruzy Tampico, 1914 [1914]. Traducción y edición de Elisa Ramírez Castañeda. México: Ediciones Toledo, 1991. 
Magdaleno, Mauricio. Escritores extranjeros en la Revolución. México: Instituto Nacional de Estudios Históricos de la Revolución Mexicana, 1979.

Meyer, Lorenzo. Las raices del nacionalismo petrolero en México [1981]. México: Océano, 2009.

Morales Padrón, Francisco. América en sus novelas. Madrid: Ediciones Cultura Hispánica del Instituto de Cooperación Iberoamericana, 1983.

Office of the Historian, Bureau of Public AfFairs. United States Department of State. "Dollar Diplomacy, 1909-1913" U.S. Department of State. 11 Mar. 2008. Artículo en línea disponible en <http://history.state.gov/ milestones/1899-1913/DollarDiplo $>$ [fecha de consulta: 3 de diciembre 2012].

Ortiz, Orlando. "B. Traven en Tampico", en La Jornada Semanal 806. México (15 de agosto de 2010): 4-5. Disponible en <http://www.jornada. unam.mx/2010/08/15/sem-orlando.html> [fecha de consulta: 3 de diciembre 2012].

Rippy, Merril. El petróleo y la Revolución Mexicana (1954). México: Instituto Nacional de Estudios Históricos de la Revolución Mexicana, 2003.

Rojas, RAfAel. "Cabrera Infante: el estilo contra la historia". Letras Libres, septiembre (2004). Artículo en línea disponible en < http://www.letraslibres.com/revista/convivio/cabrera-infante-el-estilo-contra-la-historia $>$ [fecha de consulta: 3 de diciembre 2012].

SaId, Edward W. Cultura e imperialismo [1993]. Traducción de Nora Catelli. Barcelona: Editorial Anagrama, 1996.

SÁnchez, Luis Alberto. Proceso y contenido de la novela hispano-americana. Madrid: Gredos, 1976.

Schneider, Luis Mario. "La literatura del petróleo en México” [1989], en La novela mexicana entre el petróleo, la homosexualidad y la política. México: Nueva Imagen, 1997: 15-63.

SIMPLETON MAGAZINE. "Far-fetched experimental rose. J H and the future of flowery writing", 9 marzo March 9, 1998. Artículo en línea disponible en <http://www.simpleton.com/19980309.htm> [fecha de consulta: 3 de diciembre 2012].

Tola de Habich, Fernando. Mi trato con los fantasmas. Bibliografía literaria de la Revolución mexicana. Artículo en línea disponible en < tola-tola.blogspot. $\mathrm{com} /$.../bibliografia-literaria-de-la-revolucion.html $>$ [fecha de consulta: 10 febrero 2011].

Villegas Moreno Gloria, coord. La industria petrolera en México. Cronología 1857-1998. México: Petróleos Mexicanos, 1988.

FECHA DE RECEPCIÓN: 9 de octubre de 2012

FECHA DE ACEPTACIÓN: 2 de enero de 2013 